\title{
PROPOSIÇÃO DE UMA METODOLOGIA ESTRUTURADA DE AVALIAÇÃO DO POTENCIAL REGIONAL DE REÚSO DE ÁGUA: 02 - PLANEJAMENTO TÉCNICO E ESTRATÉGICO
}

\author{
TOWARDS A STRUCTURED METHODOLOGY FOR ASSESSING REGIONAL WATER REUSE \\ POTENTIAL: 02 - TECHNICAL AND STRATEGIC PLANNING
}

Pablo da Silva Avelara, Luis Carlos Soares da Silva Juniorb, Maíra Araújo de Mendonça Limac, Ana Sílvia Pereira Santos ${ }^{c}$, Karina de Moura Costa Alencar ${ }^{c}$, Ricardo Franci Gonçalves ${ }^{d}$, José Manuel Pereira Vieirae.

aEmpresa Baiana de Água e Saneamento, ${ }^{\circ}$ Universidade Federal do Rio de Janeiro, "Universidade do Estado do Rio de Janeiro, ${ }^{d}$ Universidade Federal do Espírito Santo, ${ }^{e}$ Universidade do Minho

pablo.avelar@embasa.ba.gov.br, luis.junior@coc.ufri.br,mairalima.90@gmail.com, ana.pereira@ueri.br, kmcalencar@gmail.com,rfg822@gmail.com,jvieira@civil.uminho.pt.

Submissão: 05 de março de 2021 Aceitação: 1 de julho de 2021

\section{Resumo}

O planejamento é indispensável para o êxito dos projetos de infraestrutura urbana e rural voltados para as ações de saneamento e recursos hídricos, onde os estudos de avaliação de potencial de reúso de água estão inseridos. Nesse setor brasileiro, em que a administração pública é predominante, a morosidade das ações e a falta de planejamento levam à implantação de projetos sem garantia do alcance dos objetivos iniciais propostos. A contratação de serviços de consultoria especializada, neste caso, requer um planejamento mínimo com etapas obrigatórias a serem percorridas, tais como a elaboração do termo de referência. Este, por apresentar uma abordagem técnica, serve de caminho para outros documentos com maior carga jurídicoadministrativa, tais como o edital. Assim, a presente Nota técnica envolve aspectos relacionados ao caminho técnico para a contratação de serviços desse tipo, que levam em consideração a concepção e o planejamento do projeto. A concepção deve ser o mais abrangente possível e fiel às características gerais e específicas da região de estudo. Diferentes concepções, comparáveis entre si, levam à adoção da concepção básica que será o objeto do termo de referência. Esse, por sua vez, documento objetivo conciso e contextualizado, deve abranger minimamente os objetivos do projeto e o escopo dos produtos esperados, cronograma, responsabilidade dos envolvidos, formas de pagamento e outros. A presente Nota Técnica tem como objetivo apresentar os elementos essenciais para o planejamento das ações de reúso de água, incluindo estudos de potencial, modalidades de financiamento e definição de parcerias.

Palavras-chave: planejamento do projeto; estudo de concepção; termo de referência; parcerias; contratação.

\section{Abstract}

Planning is paramount for the success of urban and rural infrastructure projects focused on sanitation and water resources, which includes studies to evaluate water reuse potential. In Brazil, public administration prevails in these sectors. Thus, the slow pace of action and poor planning lead to projects that do not meet the initially proposed goals. Hiring specialized consulting services, in this case, requires minimum planning with mandatory steps, such as the term of reference development. Due to its technical approach, the reference term serves as a path for other documents with a higher legal-administrative lad, such as the tender process. Thus, the present Technical Note addresses technical pathways for hiring services of this kind, regarding the project's conception and planning. The ideation should be as comprehensive as possible, besides trustworthy to all the study area's features (general and specific). Different conceptions, which are comparable among themselves, result in adopting the basic design that will be the Term of Reference's goal. This, in turn, a concise and contextualized objective document, should minimally cover the objectives of the project and the scope of 
the expected products, schedule, responsibility of those involved, payment methods and others. This Technical Note aims to present all the essential elements for planning water reuse actions, including potential studies, financing modalities and definition of partnerships.

Keywords: project planning; conception study; term of reference; partnerships; contracting.

\section{INTRODUÇÃO}

Historicamente, a gestão de recursos hídricos se apresenta dissociada da gestão de saneamento básico no Brasil. Mais recentemente, com a publicação do novo Marco Legal do Saneamento no país, pela Lei 14.026/2020 (BRASIL, 2020a), as atribuições de elaboração e implantação de normas de referência para a regulação do setor saneamento, conjuntamente com o setor de recursos hídricos, foram destinadas à Agência Nacional de Águas e Saneamento Básico (ANA) (anteriormente à publicação da Lei 14.026/2020 designada somente por Agência Nacional de Águas). É nesse contexto que se espera um desenvolvimento mais harmonioso e integrado da gestão de saneamento e recursos hídricos, no país, nos próximos anos.

A universalização dos serviços de abastecimento de água e de esgotamento sanitário no Brasil, conforme previsto no ODS.6 (Objetivo de Desenvolvimento Sustentável no 6) na Agenda 2030 da Organização das Nações Unidas (UN, 2018), encontra-se ainda longe de ser alcançada: somente $61,9 \%$ do esgoto sanitário gerado é coletado e, desse montante, somente $54,1 \%$ são encaminhados até uma estação de tratamento de esgoto (ANA, 2020). Esse cenário contribui de maneira bastante negativa para a indisponibilidade hídrica que atualmente acomete algumas regiões do país, nomeadamente 0 Semiárido, em função da sua escassez natural de recursos hídricos, e a região Sudeste, em função do consumo elevado de água e o considerável montante de água poluída nos corpos hídricos.

Passa-se então a vislumbrar o esgoto sanitário como uma importante fonte de água para minimizar os impactos do estresse hídrico, que atualmente dificultam 0 desenvolvimento socioeconômico de algumas regiões, impactam a produção de alimentos provenientes do setor agrícola, geram conflitos pelo uso da água e deixam cidades inteiras sem água por períodos muitas vezes prolongados. Segundo (ANA, 2020), dos 5.570 municípios brasileiros, 2.848 decretaram situação de emergência ou estado de calamidade pública, por falta de água, no ano de
2019, sendo 1.438 situados na região Nordeste do país.

Porém, para que a prática de reúso de água a partir do esgoto sanitário seja sistematizada e institucionalizada, é necessário um esforço conjunto de planejamento técnico estratégico, que passa pelo desenvolvimento de estudos de avaliação de potencial regional de reúso de água. Em algumas regiões do país, essa fonte alternativa , pode ser responsável pela garantia de água aos diferentes usos múltiplos pretendidos na região do estudo.

Apesar desse cenário de insegurança hídrica no Brasil, Santos e Vieira (2020) afirmam que caminhos estão sendo traçados para a implementação do reúso de água no alívio das pressões sobre os recursos hídricos, ao estimarem que aproximadamente $1,5 \%$ do esgoto tratado no país é reutilizado de maneira planejada. Entretanto, avanços mais robustos devem ser aplicados e acelerados, considerando-se a segurança, a responsabilidade e o planejamento a partir do diagnóstico do potencial de reúso em um determinado contexto regional.

Planejamento pode ser entendido como um conjunto de processos, técnicas e atitudes administrativas que possibilitam a avaliação e 0 entendimento da aplicabilidade de um determinado projeto para uma tomada de decisão no presente, acarretando efeitos no futuro (ECHTERNACHT e QUANDT, 2017). As decisões tomadas no presente, refletem ações no futuro e o planejamento adequado alinha as expectativas, reduz os riscos e as incertezas e favorece o alcance dos objetivos. No setor saneamento, os processos de planejamento, quando existem, são morosos, incipientes, burocráticos e muitas vezes ineficazes. Segundo Leite e Rezende (2010), os gestores responsáveis pela prestação dos serviços públicos, onde se enquadram os de abastecimento de água e de esgotamento sanitário, devem aproveitar as oportunidades geradas pelo avanço das tecnologias da informação/comunicação e acesso às informações necessárias, estratégicas, precisas e personalizadas para que se possa realizar uma confiável tomada de decisão. 
Os estudos de potencial de reúso podem ser encarados como uma importante etapa de planejamento e absolutamente necessários para a garantia do sucesso dos empreendimentos, não devendo ser negligenciados. Para isso, as etapas de implantação passam por caminhos técnico e jurídico-administrativo. O primeiro trata da organização de um projeto com seus objetivos e fontes de financiamento até a elaboração técnica do termo de referência (TR). $O$ segundo transforma 0 TR em distintos objetos de contratação, quer em ambiente público ou privado. Diante dos diferentes caminhos jurídicoadministrativos possíveis, os autores se limitaram, no presente texto, somente à abordagem técnica.

O conjunto das Notas Técnicas (NT), perfazendo quatro conteúdos, tem como principal objetivo a proposição de uma metodologia estruturada de avaliação do potencial regional de reúso de água no Brasil. Seu foco principal é a inserção dessa fonte alternativa na matriz hídrica regional dentro do território nacional, de forma a propiciar o avanço do planejamento dos recursos hídricos e saneamento, como também, auxiliar gestores e tomadores de decisão. A presente Nota Técnica (NT02) tem como objetivo a abordagem técnica do planejamento estratégico relacionado ao desenvolvimento de estudo de avaliação do potencial regional de reúso de água.

\section{ADMINISTRAÇÃO DO SETOR SANEAMENTO NO BRASIL}

Com a publicação da Lei 14.026/2020 que, atualiza o marco regulatório do saneamento no Brasil (BRASIL, 2020a), o país inicia uma trajetória de transformação da administração dos serviços de saneamento. Até o momento, a participação pública na administração do setor é bastante superior à participação privada (BRASIL, 2020b). Entretanto, esse cenário poderá ser alterado nos próximos anos, em função do estabelecimento da necessidade de licitação na concessão dos serviços de saneamento, no novo marco regulatório (BRASIL, 2020a). Cabe ressaltar que isso não significa a privatização do setor e sim, a possibilidade da maior inserção privada, já que tanto as empresas públicas como as privadas estão aptas a participarem dos processos licitatórios; esse cenário não se enquadra à administração direta.

Atualmente, as instituições que prestam serviços de abastecimento de água e de esgotamento sanitário à população, no Brasil, também conhecidas como prestadoras de serviço, podem ser de abrangência regional, microrregional ou local, cabendo a titularidade dos serviços sempre ao município. Quanto à organização jurídico-administrativa, são classificadas como administração direta, autarquia, sociedade de economia mista, empresa pública, empresa privada e organização social (BRASIL, 2020b). Em relação somente ao serviço de esgotamento sanitário, a ANA classifica a sua organização como sendo realizada de forma indireta (delegação da prestação dos serviços para autarquia municipal, companhia estadual ou concessionária privada) ou de forma direta (sem prestador de serviço institucionalizado) (ANA, 2017).

$\mathrm{Na}$ Tabela 1, encontram-se apresentados dois aspectos relevantes para o entendimento da predominância da administração pública nos serviços de saneamento, até o momento: i) distribuição das prestadoras de serviço, segundo a abrangência jurídico-administrativa; ii) cálculo da participação percentual de empresas no setor da administração pública e da administração privada. $O$ primeiro aspecto refere-se às instituições participantes do SNIS 2019 (BRASIL, 2020b) e o segundo aspecto é resultado de um cálculo simples, por parte dos autores.

Observa-se claramente a larga maioria da participação pública (acima de $90 \%$ das empresas prestadoras de serviço) em relação à participação privada no setor saneamento no Brasil, até o ano de 2019. Mesmo com a publicação do novo marco regulatório, a inserção da participação privada tende a ser lenta. Em relação à administração direta, apesar do número considerável de prestadoras de serviço indicadas na Tabela 1 (1063 de abrangência local), em 2017, dos 5.570 municípios brasileiros, 2.588 (equivalente a pouco mais de $10 \%$ da população urbana brasileira), enquadrava-se nesse modelo, enquanto 2.982 (equivalente a $88,9 \%$ da população urbana do país) enquadravam-se na forma indireta de administração (ANA, 2017).

Diante do atual cenário de elevada participação pública na prestação de serviços de saneamento básico no Brasil e da real possibilidade da inserção privada no sistema, se pretende, com essa Nota Técnica, descrever as etapas técnicas normalmente necessárias para o desenvolvimento de projetos de avaliação de potencial de reúso de água em regiões do território nacional. Conforme destacado na NT01, trata-se de uma etapa de grande relevância para a aplicação segura e eficiente do reúso de água, 
com vistas à sua institucionalização no país.

\section{ETAPAS}

A complexidade e a exigência de uma quantidade maior ou menor de etapas a serem realizadas no estudo de potencial, depende da dimensão do projeto, do custo envolvido e das exigências e diretrizes internas da instituição responsável. Porém, algumas etapas padrão são fundamentais para a viabilidade do projeto.

De forma a facilitar a disseminação do conhecimento e para o melhor entendimento do público-alvo, foram listados e discutidos os principais aspectos relativos aos processos necessários que possibilitem a efetivação de um projeto na escala desejada (Figura 1). As etapas que compõem tais processos abordam: 1) a identificação da demanda de projeto com a sua devida contextualização; 2) o planejamento do projeto, contemplando a busca por parcerias e fontes de financiamento; 3) os pormenores da elaboração de um termo de referência, juntamente com a clara definição dos objetivos e dos produtos esperados; e 4) a implantação do projeto, que por sua vez é também objeto de um novo planejamento. Ressalta-se que as etapas listadas na presente Nota Técnica foram baseadas na experiência dos autores.

Tabela 1: Distribuição das prestadoras de serviço participantes do SNIS 2019 e participação percentual de administração pública e privada no setor saneamento

\begin{tabular}{|l|c|c|c|c|}
\hline \multirow{2}{*}{ Organização Jurídica } & \multicolumn{3}{c|}{ Abrangência } & \multirow{2}{*}{ Total } \\
\cline { 2 - 4 } & Regional & Microrregional & Local & \\
\hline Administração direta (D) & 0 & 0 & 1063 & 1063 \\
\hline Autarquia (I) & 2 & 3 & 421 & 426 \\
\hline Sociedade de economia mista (I) & 24 & 0 & 6 & 30 \\
\hline Empresa pública (I) & 1 & 0 & 5 & 6 \\
\hline Empresa privada (I) & 1 & 5 & 104 & 110 \\
\hline Organização social (I) & 0 & 0 & 5 & 5 \\
\hline Total & 28 & 8 & 1604 & 1640 \\
\hline Percentual público (\%) & 96,4 & 37,5 & 93,5 & 93,3 \\
\hline Percentual privado (\%) & 3,6 & 62,5 & 6,5 & 6,7 \\
\hline
\end{tabular}

Fonte: Dados extraídos de Brasil (2020b); Observações: D - Administração Direta ANA (2017), I - Administração indireta ANA (2017).

Figura 1: Fluxograma das etapas básicas para realização de estudos de diagnóstico de potencial de reúso

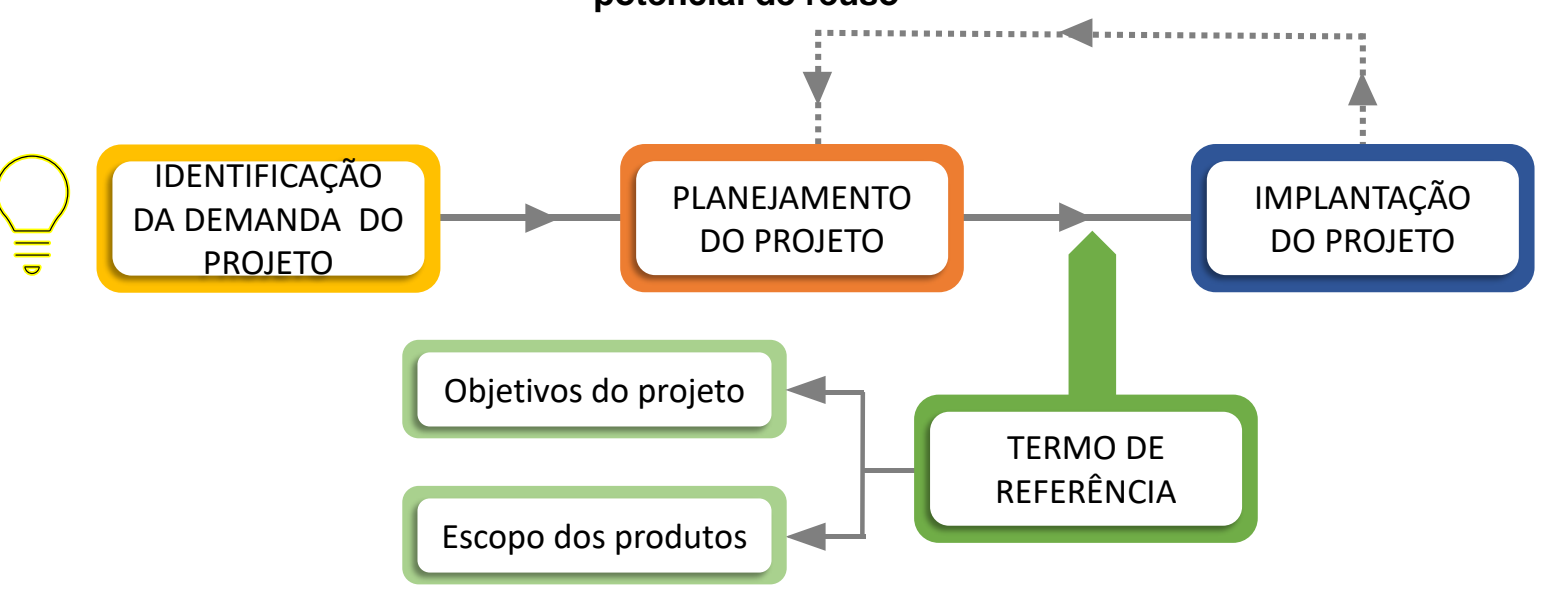

Fonte: Elaborado pelos autores. 


\subsection{IDENTIFICAÇÃO DA DEMANDA DO PROJETO}

O projeto, em geral, nasce de uma ideia, que por sua vez nasce de uma demanda específica. Essa demanda deve ser fruto de um planejamento de ações integradas do Estado que envolve as prestadoras de serviços de saneamento (públicas e privadas, de administração direta e indireta), os órgãos gestores de recursos hídricos, de meio ambiente e de saneamento, os demais órgãos públicos relacionados ao desenvolvimento socioeconômico da região, além das associações representantes da sociedade civil.

No âmbito da prestadora dos serviços de saneamento básico, as ações e as decisões relacionadas à prática de reúso de água não podem ser aleatórias e devem fazer parte desse planejamento integrado, levando em consideração os aspectos da prestação dos serviços de abastecimento de água e de esgotamento sanitário. Ainda, em geral, esse tipo de serviço pode envolver uma contratação externa, de consultoria específica e especializada, com requerimento inclusive, de comprovação técnica.

Assim, para o planejamento das ações, é necessária uma contextualização sobre o tema, levantando a importância da execução do estudo. Trata-se de uma abordagem da problemática de maneira geral e com dados específicos da região de estudo, que justifiquem o objeto do contrato, tais como os principais aspectos ambientais, culturais e socioeconômicos da região, os aspectos legais relacionados ao tema, dados gerais de disponibilidade hídrica e dos principais usuários de água, características básicas de precipitação e evapotranspiração, índice de cobertura dos serviços de esgotamento sanitário e abastecimento de água, existência de ETEs candidatas a serem produtoras e fornecedoras de água de reúso, e outros assuntos que a equipe de planejamento considerar relevantes.

A contextualização também deve abordar os maiores entraves para a efetivação da prática de reúso, no contexto regional da avaliação. Essa abordagem tem que levar em consideração a percepção dos atores sociais envolvidos na prática do reúso, que vão desde os tomadores de decisão até os usuários. Ainda, o caminho técnico, até a contratação da consultoria externa, é de responsabilidade da contratante e começa pelo planejamento do projeto, que deve estar bem alinhado com as expectativas de resultados.

\subsection{PLANEJAMENTO DO PROJETO}

Após a identificação da demanda, iniciam-se os esforços para o delineamento, o planejamento e a concepção do projeto. No contexto do saneamento básico, a Associação Brasileira de Normas Técnicas (ABNT) publicou duas Normas Brasileiras, a NBR 9648:1986 (ABNT, 1986) e a NBR 12211:1992 (ABNT, 1992), para sistemas de esgotamento sanitário e para sistemas de abastecimento de água, respectivamente, que indicam ferramentas relevantes para a concepção e a estruturação de projetos dessas naturezas. Em ambos os documentos citados são destacados requisitos gerais que devem ser avaliados e atividades técnicas específicas que devem ser definidas e executadas. Assim, no Quadro 1, estão apresentadas algumas dessas ferramentas que foram compiladas e outras que foram agregadas (atividades administrativas específicas) pelos autores para orientar o desenvolvimento do planejamento do projeto de avaliação do potencial regional de reúso de água. O planejamento ainda deve envolver aspectos relacionados às alterações climáticas, que na época do desenvolvimento das normas citadas, o assunto não tinha a relevância que tem atualmente.

É importante destacar que não é absolutamente necessário que todos esses elementos estejam alinhados e com respostas claras e definidas, na fase de planejamento do projeto. Porém, é importante que eles sejam mencionados e estudados ainda nessa etapa, para que aqueles que não estiverem alinhados, sejam incluídos com algum destaque no TR, como produto esperado da contratada.

Todos esses elementos em conjunto levam a diferentes concepções de projeto e, nessa fase de planejamento, podem viabilizar ou não o avanço da avaliação do potencial regional de reúso de água. No desenvolvimento, outras concepções podem surgir, como a transposição de bacias e a busca por outras fontes de água, alternativas ou não, mas diferentes da água de reúso. Assim, a fase de planejamento do projeto deve ser muito bem trabalhada para que diferentes concepções compatíveis entre si sejam definidas, de forma a facilitar a escolha da concepção básica que será objeto do TR. Observa-se que neste momento é fundamental a proximidade entre os técnicos da área de esgotamento sanitário e os da área de abastecimento de água, como propõe o conceito one water (única água) destacado na NT04, de 
forma a formularem propostas mais ponderadas, racionais e econômicas.

Novamente, chama-se a atenção para o nascimento da ideia, que parte do conhecimento de uma demanda específica. No caso dos estudos de avaliação de potencial regional de reúso de água, o principal propulsor é a escassez hídrica (perene ou sazonal) que demanda um planejamento adequado. Há situações em que a demanda se dá não por condições atuais de falta de água, e sim em função de previsões futuras de estresse hídrico causado, principalmente, pelo crescimento populacional, pela poluição dos corpos hídricos existentes, pelas condições climáticas locais desfavoráveis e pelas mudanças climáticas globais. Por isso, é imprescindível que esse planejamento esteja alinhado com a necessidade de confrontamento dos fatores previamente identificados pelo gerenciamento dos recursos hídricos.

Quadro 1: Ferramentas para concepção e estruturação do projeto de avaliação do potencial regional de reúso de água

\begin{tabular}{|c|c|}
\hline Item & Detalhamento \\
\hline & Requisitos iniciais \\
\hline $\begin{array}{l}\text { Características físicas, ambientais } \\
\text { e geomorfológicas }\end{array}$ & $\begin{array}{l}\text { Dados quantitativos e qualitativos dos recursos hídricos } \\
\text { (corpos receptores e mananciais de captação), características } \\
\text { de relevo, conhecimento preliminar das características do } \\
\text { solo, fauna e flora. }\end{array}$ \\
\hline Informações meteorológicas & $\begin{array}{l}\text { Dados históricos de temperatura, precipitação, } \\
\text { evapotranspiração, ventos e insolação. }\end{array}$ \\
\hline Dados demográficos & $\begin{array}{l}\text { População atual, taxa de crescimento populacional, } \\
\text { densidade demográfica, distribuição populacional em áreas } \\
\text { urbanas e rurais. }\end{array}$ \\
\hline Sistemas existentes & $\begin{array}{l}\text { Conhecimento dos sistemas de abastecimento de água e de } \\
\text { esgotamento sanitário existentes, bem como suas condições } \\
\text { gerais de operação e manutenção. }\end{array}$ \\
\hline Características de uso do solo & $\begin{array}{l}\text { Tipos de ocupação atual e prevista, bem como planos } \\
\text { diretores e documento similares de planejamento do uso do } \\
\text { solo. Avaliação da existência de cadastros rurais, urbanos e } \\
\text { de uso da água. }\end{array}$ \\
\hline Desenvolvimento socioeconômico & $\begin{array}{l}\text { Situação atual da região, bem como avaliação de crescimento } \\
\text { e possibilidade de desenvolvimento nos setores comercial, } \\
\text { industrial e agropecuário. }\end{array}$ \\
\hline Aspectos legais & $\begin{array}{l}\text { Avaliação do quadro legal nas esferas municipal, estadual e } \\
\text { federal, relacionado ao tema do projeto. }\end{array}$ \\
\hline \multicolumn{2}{|r|}{ Atividades técnicas específicas } \\
\hline $\begin{array}{l}\text { Definição do objetivo e da } \\
\text { metodologia do estudo }\end{array}$ & $\begin{array}{l}\mathrm{Na} \text { fase inicial do planejamento, muitos objetivos são } \\
\text { levantados. Posteriormente às reflexões técnicas, somente os } \\
\text { principais devem ser escolhidos, de forma a delimitar a } \\
\text { abrangência. Ainda, a definição de uma metodologia clara de } \\
\text { trabalho alinha as expectativas com os produtos finais. }\end{array}$ \\
\hline Delimitação da área & $\begin{array}{l}\text { Realizada de acordo com o escopo do projeto, com o tipo de } \\
\text { administração dos serviços de saneamento (direta ou indireta) } \\
\text { e com a abrangência: bacia hidrográfica, bacia sanitária, } \\
\text { zoneamento rural x urbano, município e estado. }\end{array}$ \\
\hline Alcance do projeto & $\begin{array}{l}\text { Estimativa de início e fim do desenvolvimento do projeto de } \\
\text { potencial e de início de implantação do empreendimento. } \\
\text { Operação de projeto piloto deve ser levada em consideração. }\end{array}$ \\
\hline $\begin{array}{l}\text { Estimativa preliminar de vazões a } \\
\text { serem consideradas }\end{array}$ & $\begin{array}{l}\text { Vazões atualmente em operação nos serviços que } \\
\text { demandam uso de água, assim como vazões esperadas. }\end{array}$ \\
\hline $\begin{array}{l}\text { Avaliação preliminar de impactos } \\
\text { ambientais }\end{array}$ & $\begin{array}{l}\text { Levantamento de aspectos ambientalmente relevantes, ainda } \\
\text { na fase de planejamento do projeto. }\end{array}$ \\
\hline
\end{tabular}




\begin{tabular}{|ll|}
\hline \multicolumn{1}{|c|}{ Item } & \multicolumn{1}{c|}{ Detalhamento } \\
\hline Estimativa de valores & $\begin{array}{l}\text { Estimativa preliminar de valores, ainda sem formalização, } \\
\text { para reflexão em relação às possíveis fontes de recursos. }\end{array}$ \\
\hline & Atividades administrativas específicas \\
\hline Setores da organização envolvidos & $\begin{array}{l}\text { Todos os setores envolvidos e principalmente os que serão } \\
\text { responsáveis pela gestão e fiscalização do contrato. }\end{array}$ \\
\hline $\begin{array}{l}\text { Recursos (não financeiros) } \\
\text { disponíveis }\end{array}$ & $\begin{array}{l}\text { Espaços físicos de trabalho (quando for o caso), bancos de } \\
\text { dados, fontes de consulta, relatórios históricos e outros que } \\
\text { favoreçam o trabalho dos desenvolvedores do projeto. }\end{array}$ \\
\hline Parcerias de cooperação técnica & $\begin{array}{l}\text { As parcerias, além de proporcionarem rapidez e eficiência na } \\
\text { transferência de conhecimento técnico entre as partes, trazem } \\
\text { celeridade aos processos de contratação inerentes ao } \\
\text { desenvolvimento de um projeto no ambiente público. } \\
\text { Ressalta-se ainda o papel da Universidade com considerável } \\
\text { conhecimento científico sobre o tema, e possibilidade de } \\
\text { desenvolver parceria em projeto de pesquisa aplicado. }\end{array}$ \\
\hline Destacado como item específico \\
\hline Financiamento
\end{tabular}

Fonte: Adaptado de (ABNT, 1986) e (ABNT, 1992).

Em geral, esses fatores estão relacionados à demanda reprimida de áreas agrícolas ou industriais, à expansão de novos empreendimentos com necessidade de grandes quantidades de água, ou ainda às áreas extremamente urbanizadas, onde os corpos hídricos já se encontram em níveis elevados de poluição e, portanto, não suportam o acréscimo de novos lançamentos de efluentes mesmo que tratados (ANA, 2020). Muitas vezes essas demandas são conjuntas no gerenciamento de uma bacia hidrográfica e, neste caso, a água de reúso pode ser a grande responsável pela minimização de conflitos pelo uso da água (MELO et al., 2020). Na maioria dos projetos se avalia inclusive a quantidade de água que deixa de ser retirada dos mananciais, favorecendo usos mais nobres como o abastecimento público. Embora sejam esses os motivos mais frequentes, as possibilidades de fundamentação da necessidade do projeto são muitas e devem se basear em pelo menos um dos aspectos técnico, econômico, ambiental e/ou social.

\section{Tipos de financiamento}

Conforme mencionado anteriormente, um item que merece destaque no projeto é o seu financiamento, considerando-se desde a fonte de fomento, até a forma de financiamento, as contrapartidas do órgão, entre outros.

Importante lembrar que a atualização do Marco Legal, Lei no 14.026 de 2020 incentiva projetos de reúso de água a partir de estações de tratamento de esgotos, que necessariamente serão viabilizados economicamente por diferentes formas de financiamento. Segundo Brasil (2020a), os contratos relativos à prestação dos serviços públicos de saneamento básico deverão dispor sobre metas de eficiência e de uso racional da água, do reúso de água, e sobre possíveis fontes de receitas alternativas, complementares ou acessórias, bem como as provenientes de projetos associados, incluindo, entre outras, a alienação e o uso de efluentes sanitários para a produção de água de reúso, com possibilidade das receitas serem compartilhadas entre o contratante e o contratado, caso aplicável.

Assim, alguns tipos de financiamento estão aqui destacados para que possam viabilizar economicamente a implantação de estudos sobre potencial de reúso em qualquer região do Brasil, seja ente público, privado ou microempresas. São eles: BNDES Finem - Saneamento ambiental e recursos hídricos, Programa Saneamento para Todos da CAIXA e FINISA - Financiamento à Infraestrutura e ao Saneamento da CAIXA. O objetivo dos autores nessa seção é tão somente o de demonstrar alguns caminhos, mas ressalta-se que muito outros similares encontram-se à disposição, inclusive em órgãos internacionais.

\section{BNDES Finem - Saneamento ambiental $e$ recursos hídricos}

No âmbito do BNDES Finem, podem participar empresas sediadas no país, fundações, associações e cooperativas, entidades e órgãos 
públicos. As condições de financiamento dependem do porte do cliente, a partir de uma receita operacional bruta anual, mínima de $\mathrm{R} \$ 360$ mil /ano. Assim, de acordo com BNDES (2020), nesse programa de financiamento, os estudos sobre o potencial regional de reúso podem ser enquadrados dentro do grupo de serviços nacionais em duas categorias, conforme detalhado no Quadro 2.

O Programa Saneamento para Todos, da Caixa Econômica Federal, visa financiar empreendimentos ao setor público e ao setor privado com recursos oriundos de Fundo de
Garantia do Tempo de Serviço - FGTS e da contrapartida do solicitante. Se enquadram na categoria de "setor Público", os estados, municípios, Distrito Federal, concessionárias públicas de saneamento, consórcios públicos de direito público e empresas públicas não dependentes. No "setor privado" enquadram-se as concessionárias ou sub-concessionárias privadas de serviços de saneamento básico, ou empresas privadas, organizadas na forma de sociedade de propósito específico para o manejo de resíduos sólidos e manejo de resíduos da construção e demolição.

Quadro 2: Detalhamento das categorias do programa de financiamento "BNDES Finem" apropriadas aos estudos de avaliação de potencial regional de reúso de água

\begin{tabular}{|c|c|c|}
\hline \multirow{2}{*}{ Item } & \multicolumn{2}{|c|}{ Detalhamento } \\
\hline & Inclui & Não inclui \\
\hline $\begin{array}{l}\text { Serviço técnico especializado } \\
\text { Estudos e projetos }\end{array}$ & $\begin{array}{l}\text { Estudos e projetos de } \\
\text { engenharia básica, engenharia } \\
\text { detalhada, plano de urbanismo, } \\
\text { plano de revitalização e } \\
\text { similares, prévios à } \\
\text { implantação do } \\
\text { empreendimento, mesmo os } \\
\text { realizados por equipe própria. }\end{array}$ & $\begin{array}{l}\text { Gastos regulatórios ou com } \\
\text { licenciamento, gastos pré- } \\
\text { operacionais, e serviços } \\
\text { técnicos especializados } \\
\text { (consultorias e certificações). } \\
\text { Estes podem ser incluídos em } \\
\text { outras modalidades. }\end{array}$ \\
\hline $\begin{array}{l}\text { Serviço técnico especializado } \\
\text { P\&D }\end{array}$ & $\begin{array}{l}\text { Contratação de serviços } \\
\text { relacionados à pesquisa e } \\
\text { desenvolvimento de novos } \\
\text { produtos, processos e serviços, } \\
\text { bem como contratação de } \\
\text { testes e ensaios em projetos de } \\
\text { P\&D. }\end{array}$ & $\begin{array}{l}\text { Remuneração de equipe } \\
\text { própria do projeto, tais como: } \\
\text { gastos com mão-de-obra } \\
\text { diretamente relacionada ao } \\
\text { projeto, inclusive equipe própria } \\
\text { de P\&D. }\end{array}$ \\
\hline
\end{tabular}

Fonte: Adaptado de (BNDES, 2020).

Programa Saneamento para Todos (CAIXA)

Nesse programa, os estudos sobre o potencial de reúso local podem ser enquadrados dentro da modalidade "Estudos e Projetos" que se destinam a diversas produções, como: planos municipais e regionais relativos ao saneamento básico, estudos de concepção e projetos para empreendimentos com foco nas áreas de saneamento básico, manejo da construção e demolição e preservação de mananciais.

Ressalta-se que, de acordo com CAIXA (2020), a modalidade de esgotamento sanitário é destinada ao incentivo para elevar os índices de coleta, tratamento e destinação final adequados de efluentes. Novamente levanta-se a importância de se indicar a prática de reúso de água como uma forma adequada de destino final de águas residuárias.

FINISA - Financiamento à infraestrutura e ao saneamento (CAIXA)

A FINISA auxilia no aumento na qualidade da vida da população, através da geração de empregos e renda por meio de diversos empreendimentos de infraestrutura contempladas por essa linha de financiamento (CAIXA, 2020). As modalidades abrangidas pela FINISA são as de estudos de viabilidade técnico-econômica de reúso nos municípios, estados e no Distrito Federal. Nesse tipo de financiamento, o ente público pode reivindicar recursos de apoio financeiro em ações orçamentárias em 
andamento, como, por exemplo, investimentos em infraestrutura, construção de escolas, hospitais, entre outros.

\subsection{ELABORAÇÃO DE TERMO DE REFERÊNCIA}

O termo de referência (TR) é um objeto importante do processo de contratação de consultoria externa e de desenvolvimento de estudos internos, tanto na administração pública como na privada, que visa norteá-la. Assim, o TR deve ser produzido a partir de estudos preliminares e conter elementos necessários e suficientes, com nível de precisão adequado para caracterizar o objeto da contratação (BRASIL, 1993).

No contexto do saneamento básico, onde se enquadra a prática de reúso de água, a Fundação Nacional de Saúde (FUNASA) publicou em 2018 o documento intitulado "Termo de Referência para Elaboração de Plano Municipal de Saneamento Básico", que tem forte relação com o objeto de estudo do presente conjunto de Notas Técnicas, embora seja direcionado especificamente à elaboração dos planos municipais de saneamento básico (FUNASA, 2018). Nesse documento, a FUNASA indica os seguintes recortes que podem também ser aplicados ao estudo de avaliação de potencial regional de reúso de água: substantivo, territorial e temporal. $O$ recorte substantivo indica a abrangência ou o serviço de reúso de água a ser prestado no contexto da gestão de recursos hídricos e saneamento; o recorte territorial indica o espaço físico de abrangência do estudo (nas áreas rurais e urbanas), tais como município, estado, bacias hidrográficas e/ou de esgotamento, áreas agrícolas, distritos industriais; o recorte temporal refere-se à abrangência do horizonte do projeto (FUNASA, 2018). Todos os três recortes, conjuntamente, definem o objeto principal do TR que deve ser claro, objetivo e específico para o que se espera.

Destaca-se que a elaboração do TR, bem como a concepção anteriormente apresentada, deve buscar articulação com as políticas de desenvolvimento urbano e rural, de habitação, de combate à pobreza e de sua erradicação, de proteção ambiental, de recursos hídricos e saneamento, de promoção à saúde, de segurança alimentar e outras, de relevante interesse socioeconômico, voltadas para a melhoria da qualidade de vida e da minimização dos impactos da indisponibilidade hídrica.
No TR são delimitadas as responsabilidades da contratante e da contratada, produtos esperados, cronograma de entregas, formas de pagamento e os valores dos produtos. De acordo com Brasil (1993), e adaptado ao contexto desse conjunto de Notas Técnicas, o TR deve expressar as informações diversas levantadas em torno de um dado objeto ou serviço, que servirá tanto como fonte para guiar a aquisição ou a contratação dos serviços almejados, como para o desenvolvimento de estudos internos, na própria instituição. Para tanto, o TR deve conter elementos necessários e suficientes, com nível de precisão adequado, para caracterizar o objeto da contratação, elaborado com base nas indicações dos estudos técnicos preliminares, que assegurem a viabilidade técnica e ambiental, e que possibilite a avaliação do custo do serviço e a definição dos métodos e do prazo de execução.

No caso da avaliação do potencial de reúso em uma determinada região, são fundamentais a descrição do conhecimento geral e específico (estado da arte) e a contextualização do arcabouço legal na região em que o projeto será desenvolvido. As muitas regiões do território brasileiro são marcadas por grandes diferenças ambientais, culturais e socioeconômicas, que demandam avaliações específicas para conhecimento aprofundado dessas particularidades locais.

Atualmente, é comum no Brasil o desenvolvimento de projetos de sistemas de esgotamento sanitário e de abastecimento de água que não levam em consideração as particularidades locais e regionais, muito menos um estudo de concepção que considere a possibilidade do reúso de água. Esse é um dos principais motivos pelos quais muitos desses sistemas operam de forma insatisfatório no país (MORAES et al., 2020). Nesse sentido, o TR para realização de estudos de potencial de reúso de água deve exigir a contextualização regional, de forma a garantir a aplicabilidade real dos projetos provenientes do estudo de potencial. É neste momento, de elaboração do TR, que essas necessidades são amarradas e as expectativas são alinhadas, para o alcance dos objetivos pretendidos.

Um TR incompleto ou inconsistente leva à dificuldade de se selecionar a proposta mais vantajosa e/ou a um contrato sem mecanismos adequados para a gestão contratual. Esse cenário tem como consequência o não alcance dos objetivos inicialmente elencados na fase de 
planejamento do projeto e o desperdício de recursos.

Por fim, um ponto a se destacar na elaboração do TR é que ele deve ser o mais sucinto e objetivo possível, a fim de não trazer dúvidas à contratação e execução dos serviços contratados. Entretanto, devem ser considerados todos os elementos necessários para o adequado desenvolvimento do projeto e, neste caso, é melhor "pecar pelo excesso do que pela omissão". $\mathrm{Na}$ presente Nota Técnica, são sugeridas as abordagens para os objetivos do projeto e o escopo dos produtos, mas ressalta-se que outros elementos importantes e direcionados a cada projeto devem ser incorporados, tais como cronograma, regras da contratação, formas de pagamento, valores financeiros associados, entre outros.

\section{Objetivos do projeto}

Os objetivos, alinhados às expectativas da fase de planejamento do projeto, devem ser divididos em geral e específicos, de forma a facilitar tanto 0 entendimento por parte da contratada, como o delineamento dos produtos esperados.

O objetivo geral aborda a questão principal do certame, que, neste caso, trata-se de um estudo de avaliação e/ou de diagnóstico, a fim de explorar as potencialidades de reúso de água a partir de efluente de estações de tratamento de esgotos da região de estudo. Os objetivos específicos propõem um delineamento das ações que levarão ao alcance do objetivo geral, a partir da confecção dos produtos definidos. Assim, os objetivos gerais devem abranger os seguintes aspectos, que devem ser adaptados de acordo com as particularidades de cada escopo:

- Apresentar um estado da arte sobre aspectos legais, práticos e tecnológicos de reúso de água no Brasil e no mundo, de forma a esclarecer o contexto do estudo e subsidiar as tomadas de decisão. Detalhes dos aspectos legais podem ser observados na NT01;

- Identificar e caracterizar as ETEs em funcionamento ou em planejamento de implantação, com vistas à adaptação para produção de água de reúso para diferentes finalidades (NT03);

- Estudar e apresentar diferentes opções de tecnologias para adequação de ETEs em operação e em fase de projeto, à produção de água de reúso para diferentes finalidades. Nesse caso é imprescindível que se levem em consideração, tecnologias adequadas às características locais da área de estudo. Para isso, os projetos de PD\&l (Pesquisa, Desenvolvimento e Inovação) podem ser de grande valia para fomentar a redução da dependência tecnológica que atualmente impõe especificidades extremamente avançadas para a condição brasileira, custos de importação de insumos elevados e manutenibilidade dos equipamentos comprometida.

- Identificar e caracterizar qualitativa e quantitativamente as principais demandas de água da região de estudo, atuais e futuras, considerando-as como os potenciais usuários da água de reúso (NT03);

- Definir particularidades relacionadas aos ambientes urbano e rural, que necessariamente adotam diferentes premissas para a reutilização de água. É importante referir que em ambos, os sistemas podem ser descentralizados (exemplos nas NT01). Em ambiente rurais, destacam-se as unidades agrícolas familiares para os sistemas descentralizados. Para o caso dos ambientes urbanos, apresenta-se uma abordagem de tendência na NT04, ao considerar como desafio, a gestão integrada de águas residuais, com a interrelação entre os sistemas centralizados e os descentralizados;

- Para o caso específico do reúso de água na agricultura, mapear os produtores rurais e suas principais características, como tipos de culturas a serem irrigadas, quantidade de água necessária, qualidade exigida para a água, períodos específicos que demandam irrigação, equipamentos utilizados na irrigação e outros;

- Definir e apresentar critérios para o desenvolvimento da cultura de conservação, uso racional e reúso de água na região de estudo. Este é um dos principais desafios apresentados na NT04, no contexto da "capacitação continuada"; 
- Dependendo do porte do projeto, é interessante solicitar a produção de mapas, conforme apesentado na NT03, utilizando a ferramenta SIG, para georreferenciamento, minimamente dos potenciais produtores e usuários da água de reúso. De maneira mais aprofundada, é possível ainda delimitar distâncias entre eles, definir regiões com exigências de diferentes qualidades de água, tipos de culturas a serem irrigadas no ambiente rural, de forma a facilitar a tomada de decisão para a implantação dos futuros projetos de reúso;

- Definir aspectos relacionados à implantação de projeto-piloto, tais como área prioritária, ETE de estudo, usuário específico e outros. Nesse caso, a Universidade ou um centro de pesquisa pode ser um importante aliado na condução do monitoramento do projetopiloto (NT04);

- Realizar estudo de viabilidade econômica do reúso de água, definindo os índices financeiros e informando os custos fixos, variáveis, ponto de equilíbrio, investimento etc. $O$ foco é avaliar se o novo empreendimento será de fato sustentável economicamente na região.

- Por fim, pode ser interessante ainda, finalizar o estudo de potencial, com a apresentação de um TR (de projetos básico e executivo) e de um orçamento já com vistas à efetivação da prática de reúso de água no âmbito do projetopiloto ou do projeto real, de acordo com o porte do estudo.

É fundamental uma clara definição dos objetivos para o projeto, uma vez que o documento é a interface entre o proponente e o executor. Portanto, essa etapa e a seguinte, de definição do escopo dos produtos, são essenciais para 0 sucesso do estudo.

\section{Escopo dos produtos}

Os produtos são divididos por temas a fim de facilitar a gestão do contrato, com o atendimento claro aos objetivos propostos inicialmente, em uma ordem cronológica também definida no planejamento do projeto. A divisão dos produtos por tema e por ordem cronológica é estratégica por favorecer o andamento do estudo, facilitar a disponibilização de dados que estão sob a tutela do contratante, e apoiar o pagamento dos serviços a partir da entrega e aprovação de cada produto.

Nesse momento, uma forma interessante de amarração dos objetivos aos produtos, e posteriormente ao cronograma, é indicar no escopo de cada produto os objetivos que se almejam alcançar em cada um; o mesmo pode ser realizado na elaboração do cronograma. Essa ação permite aos gestores e à equipe responsável pela elaboração do TR, uma avaliação mais aprofundada sobre a abrangência dos aspectos inicialmente definidos como objeto do estudo. Ainda, sugere-se a criação de um check list para garantir que todos os aspectos discutidos e aprovados na fase de planejamento do projeto tenham sido contemplados em todos os produtos.

Destaca-se que independentemente da definição do escopo de cada produto, o primeiro deles deve ser o Plano de Trabalho, que deve ser apresentado após a conclusão do certame e assinatura da ordem de serviço com a contratada. Trata-se de uma etapa essencial para um novo planejamento (já voltado para a execução do objeto) e para a correta condução do estudo. O Plano de Trabalho é a materialização do planejamento, contemplando todas as atividades estabelecidas no escopo de cada produto do TR. Nesse produto, a contratada deverá apresentar de forma detalhada, como, quando e por quem serão realizadas as atividades.

$\mathrm{Na}$ definição do escopo desse produto (Plano de Trabalho), que norteará o desenvolvimento dos demais, é possível definir aspectos básicos a serem nele contemplados, tais como:

- Descrição das atividades que serão executadas, com suas respectivas especificidades.

- Cronograma detalhado e baseado naquele mais abrangente definido no TR; quando possível, devem ser alocadas as reuniões de grande porte e os eventos de gestão participativa, quando couber.

- Organograma básico que reflita as ações e seus respectivos responsáveis, por parte da contratada; se possível e a depender do porte do estudo, podem ser definidos os pares da contratante responsáveis pelas ações.

- Métodos ou metodologias de desenvolvimento das atividades propostas para desenvolvimento dos 
demais produtos; devem ser bem estruturados, com a aprovação da contratante, de forma a garantir a exequibilidade do estudo, com a participação efetiva de todos os envolvidos, no recorte temporal proposto.

Para efeito de ilustração e facilitação do entendimento, no Quadro 3 estão apresentados os produtos e seus respectivos escopos, definidos no TR do projeto conduzido pela Empresa Baiana de Águas e Saneamento (EMBASA), no período compreendido inicialmente entre outubro de 2019 e novembro de 2020, intitulado "Diagnóstico do potencial de reúso de efluentes no estado da Bahia" (EMBASA, 2019). Por motivo de acréscimo de um novo produto (Resumo executivo), no decorrer do desenvolvimento do projeto o prazo final foi alterado para janeiro de 2021. Esse TR, por ser de acesso público, está apresentado no Material Suplementar da presente Nota Técnica.

Embora os autores tenham indicado na NT01 que o termo correto a ser utilizado para designar a prática seja "reúso de água", em detrimento ao termo "reúso de efluente", o segundo foi adotado no Quadro 3, de forma a refletir com fidelidade os produtos definidos no estudo citado. Ainda para efeito de esclarecimento, o objetivo geral desse estudo foi a realização de um diagnóstico de potencialidades do reúso de água a partir dos efluentes gerados nas ETEs do estado da Bahia, operadas pela EMBASA, identificando, caracterizando, quantificando e qualificando os potenciais produtores (oferta) e usuários (demanda) de água de reúso (EMBASA, 2019).

Destaca-se ainda que os produtos devem ser entregues em linguagem adequada, com informações sistematizadas, em forma de relatórios descritivos, com registros fotográficos, planilhas, gráficos, entre outros elementos julgados necessários para cada produto. Todos esses elementos devem estar explicitados no termo de referência.

Apesar de não abordado diretamente nos Produtos descritos no TR do projeto da EMBASA, os autores recomendam fortemente a inclusão de um, relacionado à dimensão econômica, no sentido de se definir critérios para a tarifação da água de reúso. É ela que vai permitir a operacionalização do empreendimento, levandose em consideração que obviamente, ele deve se pagar ao longo dos anos.

De acordo com Fonseca e Gabriel (2015), a tarifação de água de abastecimento no Brasil não é uma tarefa simples, não obstante os seus inúmeros benefícios associados principalmente ao estímulo ao uso racional e à consideração dessa como a fonte primária mais adequada e racional para o financiamento dos serviços públicos que admitem essa forma de remuneração.

Segundo Speers (2007), os custos dos prestadores de serviços de saneamento podem ser divididos em: operacionais, de capital e de reposição. Os operacionais envolvem o custo de recursos como materiais de energia, recursos humanos, produtos químicos e aluguéis de espaços; os de capital referem-se ao custo de obtenção de capital, incluindo um retorno sobre o investimento feito; e os de reposição abordam o custo da substituição ou reparação de bens à medida que se gastam.

Nesse contexto, tal como para a tarifação de água de abastecimento, a da água de reúso deve empregar como estratégia da gestão de custo, a identificação e as cadeias de formação dos custos característicos dos 3 setores indicados por Speers (2007), além das estratégias de gestão de demandas, investimentos e políticas tarifárias (ANJOS JR., 2001). Estrutura similar pode ser adotada no caso da água de reúso, onde pesem as particularidades relativas à necessidade de adequação das tarifas à situação socioeconômica dos usuários, como uma característica marcante no Brasil. É preciso, ainda, ter-se em consideração que os custos de produção, reservação e distribuição devem necessariamente estar embutidos na tarifa, de modo a se prever o retorno em tempo razoável no contexto do investimento.

No Brasil, o esquema de reúso de água oferecido pela SANASA, destacado na NT01, apresenta de forma transparente não só o valor da tarifa, como também as modalidades de compra da água de reúso. Atualmente (2021), a SANASA faz entrega de volumes de $7 \mathrm{~m} 3$ ou $14 \mathrm{~m} 3$, no próprio município de Campinas/SP, com valores correspondentes à $R \$ 290,19$ e 369,34, respectivamente; ou permite a retirada pelo solicitante, na Estação de Produção de Água de Reúso (EPAR), com caminhão próprio, no valor de $\mathrm{R} \$ 2,25 / \mathrm{m} 3$ (SANASA, 2021).

Em Israel, país conhecido pela exploração eficiente e exitosa da prática de reúso de água, a tarifa da água de reúso para irrigação em 2017, encontrava-se no valor médio de US\$ 0,28, inferior ao de captação da água superficial (US\$ 0,46) e ao da água dessalinizada (US\$ 0,33) (MARIN et al., 2017). De acordo com Araujo et al. (2017), 
Israel apresenta tarifas de água para uso na irrigação bem acima do que agricultores pagam na maioria dos países ao redor do mundo, e abaixo dos valores atribuídos à água superficial e à água dessalinizada no país, incentivando o uso racional da água e o desenvolvimento de práticas agrícolas modernas.

Quadro 3: Produtos definidos no termo de referência do projeto "Diagnóstico do potencial de reúso de efluentes no estado da Bahia" - EMBASA

\begin{tabular}{|c|c|}
\hline Produto & Escopo resumido \\
\hline $\begin{array}{l}\text { Produto 1: } \\
\text { Plano de trabalho }\end{array}$ & $\begin{array}{l}\text { Deve apresentar a descrição das atividades, cronograma, } \\
\text { fluxograma, métodos de desenvolvimento dos serviços e } \\
\text { organização para a sua execução, com indicação dos eventos } \\
\text { necessários, conforme o escopo básico apresentado no TR. }\end{array}$ \\
\hline $\begin{array}{l}\text { Produto 2: } \\
\text { Diagnóstico do potencial de reúso } \\
\text { de efluentes no estado da Bahia }\end{array}$ & $\begin{array}{l}\text { Deve pesquisar, coletar informações, processar e analisar } \\
\text { todos os elementos e dados existentes disponíveis e } \\
\text { envolvidos na área de estudo, tais como: dados quantitativos } \\
\text { e qualitativos das ETEs, potenciais usuários da água de reúso } \\
\text { pertencentes à cadeia produtiva da região, dados gerais da } \\
\text { área como características socioeconômicas, ambientais e } \\
\text { culturais. } \\
\text { Deve levantar e apresentar soluções tecnológicas de } \\
\text { adequação à qualidade desejada para o reúso e adequadas } \\
\text { às particularidades regionais. }\end{array}$ \\
\hline $\begin{array}{l}\text { Produto 3: } \\
\text { Mapa temático com os potenciais } \\
\text { de reúso de efluente no estado da } \\
\text { Bahia }\end{array}$ & $\begin{array}{l}\text { Deve apresentar mapa temático dinâmico, com acesso fácil e } \\
\text { amigável ao conteúdo das informações coletadas, } \\
\text { considerando basicamente: localização das ETEs e seus } \\
\text { pontos de lançamento, regiões e localidades com potencial } \\
\text { para efetivação da prática de reúso (produtores e usuários) e } \\
\text { definição e marcação de áreas prioritárias. }\end{array}$ \\
\hline $\begin{array}{l}\text { Produto 4: } \\
\text { Manual de orientações e práticas de } \\
\text { reúso de efluente tratado }\end{array}$ & $\begin{array}{l}\text { Deve apresentar modelo padrão, com especificações } \\
\text { mínimas, visando a prática de reúso no futuro, descrevendo: } \\
\text { qualidade do efluente, tipificação das modalidades de } \\
\text { tratamento, formas de armazenamento, sistema de } \\
\text { distribuição dos efluentes a serem reutilizados, tecnologia } \\
\text { apropriada à especificidade do local e potenciais usuários. }\end{array}$ \\
\hline $\begin{array}{l}\text { Produto 5: } \\
\text { Termo de referência para projeto- } \\
\text { piloto de reúso de efluentes no } \\
\text { estado da Bahia }\end{array}$ & $\begin{array}{l}\text { Deve apresentar um TR para contratação de projeto básico e } \\
\text { executivo de reúso de efluentes, de acordo com as } \\
\text { características de uma área identificada preliminarmente } \\
\text { durante o desenvolvimento do Produto } 2 \text {, e com sua escolha } \\
\text { devidamente justificada. }\end{array}$ \\
\hline $\begin{array}{l}\text { Produto 6: } \\
\text { Resumo Executivo }\end{array}$ & $\begin{array}{l}\text { Deve ser apresentado um documento com a compilação de } \\
\text { todas as informações apresentadas durante o projeto, com } \\
\text { ilustrações, gráficos e tabelas que facilitem o entendimento } \\
\text { dos leitores. Além de publicizar o projeto, almeja-se } \\
\text { apresentar de forma clara e objetiva todo o seu } \\
\text { desenvolvimento. }\end{array}$ \\
\hline
\end{tabular}

Fonte: Adaptado de EMBASA (2019).

3.4 .

\section{IMPLANTAÇÃO DO PROJETO}

No Brasil, frequentemente, os projetos de saneamento básico são implantados sem concepção adequada, levando ao incumprimento dos seus objetivos. E não raro, mesmo quando os estudos de concepção são bem desenvolvidos e formulados com bases sólidas, os projetos acabam não sendo implantados ou sofrendo adaptações para se encaixarem aos recursos 
financeiros disponíveis.

Nesse sentido, para garantia da implantação da infraestrutura de uma prática de reúso de água responsável e segura, o estudo de potencial deve apresentar todas as nuances conforme já destacado até o momento. Além disso, para garantia dessa implantação, é necessário que o estudo incorpore instrumentos bem alinhados e estruturados, tanto no contexto da administração pública como no da administração privada.

No exemplo apresentado no Quadro 3, a EMBASA definiu como Produto 5 do estudo de potencialidades contratado, a elaboração de um TR para implantação e operação de um projeto piloto, previamente à sistematização da prática na empresa e no estado. Conforme é destacado na NT04, o projeto piloto tem funções específicas de permitir o desenvolvimento de uma experiência prática anteriormente à implantação de projetos definitivos, além de, a partir da publicação de dados transparentes, criar um elo de confiança com os demais envolvidos (produtores, consumidores, reguladores, fiscalizadores e sociedade).

Dependendo do porte do projeto e das condições e das características do estudo de potencial, o projeto piloto não se aplica, apesar da forte indicação (MUKHEJEERE e JENSEN, 2020; ANGELAKIS et al., 2018; FIELDING et al., 2019), principalmente no sentido de ganho de experiência operacional e de confiança dos envolvidos. Nesse caso, um dos produtos da contratação, pode ser o TR para implantação direta do empreendimento. Nesse sentido, o objetivo é primar pela implantação do projeto, considerando todos os aspectos definidos no estudo de avaliação de potencial regional de reúso de água. Seguindo essa lógica o fluxograma da Figura 1 demonstra a interação entre a implantação e o planejamento do projeto.

\section{DEFINIÇÃO DAS PRINCIPAIS PARTES INTERESSADAS}

Para o início e o bom andamento do projeto, a identificação das partes interessadas é importante no sentido de se realizar ações e manter o engajamento (MARTINS e SOUZA NETO, 2017). Para tal, a seguir são apresentados 6 tipos de parceiros que se configuram como partes interessadas a serem consideradas no desenvolvimento de um estudo de avaliação do potencial regional de reúso de água. Tratam-se, essencialmente, de parceiros institucionais, relacionados à disponibilização de dados, definição de critérios de licenciamento, regulação e fiscalização, detentores de amplo conhecimento específico sobre o tema e representação da sociedade civil envolvida direta e indiretamente. Para cada projeto, em decorrência de diferentes escopos, abrangências e portes, outras parcerias podem ser incorporadas.

1) Prestadoras de serviço de esgotamento sanitário e de abastecimento de água, representados por administração direta, autarquia, sociedade de economia mista, empresa pública, empresa privada ou organização social, conforme definido por Brasil (2020b). Essas instituições são fundamentais para o fornecimento de dados relacionados a ofertas $e$ demandas potenciais de água de reúso. As ofertas são representadas pelas ETEs em operação e em planejamento, que se configuram como as principais fornecedoras de água de reúso. As demandas são representadas pelos usuários de grandes quantidades de água no ambiente urbano, que podem representar candidatos a consumidores de água de reúso, tais como distritos industriais, companhias municipais de limpeza urbana, setores da prefeitura responsáveis pela conservação das vias públicas, parques e jardins, empresas que operam (e lavam) veículos especiais, e setores da construção civil.

2) Associações de produtores rurais, que representam grandes consumidores de água para atividades agrossilvipastoris, e associações de representação industrial, que se configuram como grandes consumidores de água em distritos industriais. Os produtores rurais são atores importantes e parceiros primordiais em estudo de avaliação de potencial de reúso de água na irrigação, enquanto as indústrias, no reúso industrial. Assim, devem ser envolvidos desde o início dos estudos, de forma a contribuírem com dados para o desenvolvimento do projeto e no futuro poderem ser efetivos consumidores. Essa participação, ao longo do desenvolvimento do estudo, garante engajamento e maior comprometimento 
com as ações de implantação dos projetos no futuro, além de minimizar os impactos da rejeição psicológica natural à prática de reúso, que está abordada com destaque na NT04, como um dos principais desafios.

3) Além dos fornecedores e usuários, as entidades regulatórias, como as secretarias e institutos de meio ambiente, vigilância sanitária, além de agências reguladores de saneamento, possuem papel importante em projetos de reúso de água. Essas instituições são responsáveis por desenvolver as regulações e regulamentações para aplicação da prática, aspectos de licenciamento e definição de tarifas, assim como, fornecimento de dados para levantamento de demandas, como o cadastro de usuários outorgados em uma bacia hidrográfica de interesse.

4) Universidades e centros de pesquisa que concentram capacidade técnica e intelectual em relação ao tema. As parcerias com essas instituições, de preferência em convênios e/ou em projetos de PD\&I, são bastante bem vindas na condução de pesquisas específicas, combinadas com as demandas do projeto e de se fornecer conhecimento adequado e atualizado para o desenvolvimento exitoso do estudo.

5) Às entidades que atendem à sociedade civil cabe 0 papel de representar a sociedade na fiscalização dos projetos e ações. Nessa categoria, destacam-se os comitês de bacia hidrográfica, que possuem grande conhecimento dos recursos hídricos contidos em sua delimitação geográfica; os conselhos de recursos hídricos e meio ambiente, cuja função normativa fornece segurança técnica aos tomadores de decisão; além dos ministérios públicos que possuem papel fundamental na defesa e resolução de conflitos de interesse público. Aqui, destaca-se que os comitês de bacias hidrográficas, por meio de suas agências delegatárias ou órgão executivo, que já administram recursos financeiros advindos da cobrança pelo uso da água, podem ser executores de projetos desse tipo. Ainda, a sociedade civil deve ser abordada no contexto da gestão participativa dos projetos de recursos hídricos e saneamento básico.

6) Por fim, o governo, em suas diversas instâncias como, o poder legislativo, ministérios e secretarias relativas ao meio ambiente e recursos hídricos, tem como função o desenvolvimento de propostas de leis, decretos e regulamentos, bem como elaboração, execução e monitoramento de programas e ações relacionados às políticas existentes, visando a aplicação dos recursos financeiros.

\section{CONSIDERAÇÕES FINAIS}

Os principais aspectos técnicos para elucidar o caminho para a contratação e desenvolvimento de estudos de avaliação de potencial regional de reúso de água no território brasileiro foram abordados e detalhados na presente Nota Técnica. Assim, as considerações finais abordam um roteiro básico, apresentado na Figura 2, que pode ser facilmente adotado pelos desenvolvedores de trabalhos dessa natureza, considerando-se, claro, a inserção de novos elementos, de acordo com as particularidades e porte do projeto. Nela, observam-se os elementos principais, os seus aspectos específicos e as suas interrelações. Essas interações são responsáveis pelas definições e amarrações dos aspectos técnicos de forma a garantir que no caminho jurídico-administrativo não haja perda de qualificação técnica do projeto.

\section{AGRADECIMENTO}

Os autores agradecem ao Sr. César Silva Ramos, Diretor Técnico e de Planejamento da Empresa Baiana de Águas e Saneamento EMBASA, por acreditar e incentivar a produção desse conteúdo, bem como à Gerência de Tecnologia Operacional -TDOT, unidade onde está lotado um dos autores desta nota. 
Figura 2: Roteiro básico aplicado ao desenvolvimento de estudo de avaliação de potencial regional de reúso desde o planejamento até a implantação do empreendimento e/ou projeto piloto

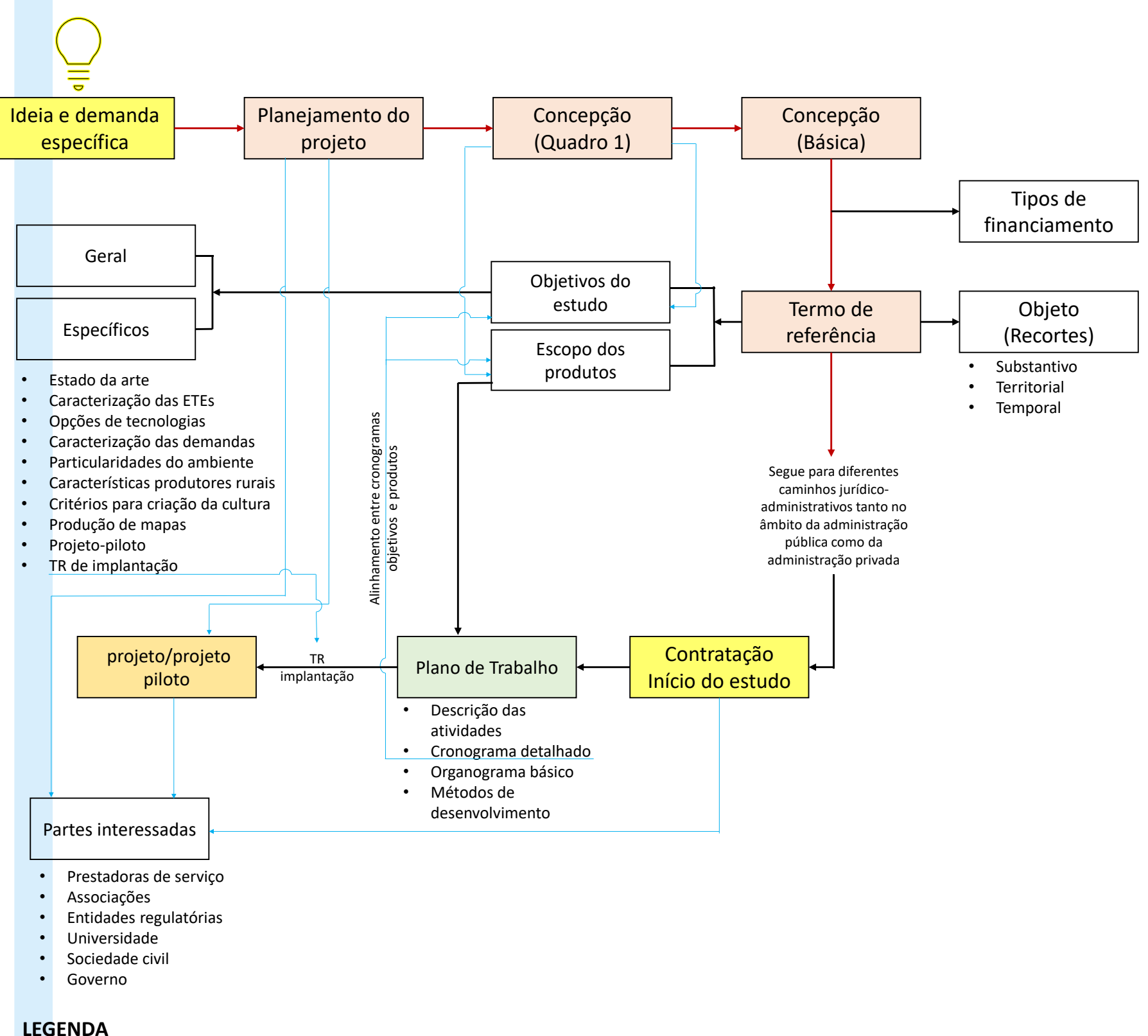

LEGENDA

Caminho dos elementos principais

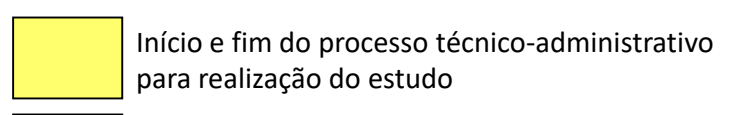

Caminho dos aspectos específicos dos elementos principais

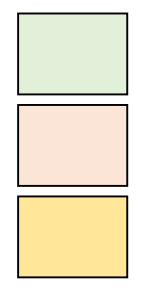

Marco do ínicio do estudo

Elementos pricipais técnicos

Interrelação entre aspectos

Início da etapa de implantação

Fonte: Elaborado pelos autores. 


\section{REFERÊNCIAS}

ABNT. ASSOCIAÇÃO BRASILEIRA DE NORMAS TÉCNICAS. ABNT NBR 9648: Estudo de concepção de sistemas de esgoto sanitário - Procedimento. Rio de Janeiro. 1986.

ABNT. ASSOCIAÇÃO BRASILEIRA DE NORMAS TÉCNICAS. ABNT NBR 12.211: Estudos de concepção de Sistemas Públicos de Abastecimento de Água. Rio de Janeiro. 1992.

ANA. Agência Nacional de Águas (Brasil). Atlas esgotos: despoluição de bacias hidrográficas / Agência Nacional de Águas, Secretaria Nacional de Saneamento Ambiental. Brasília: ANA, 2017.

ANA. Agência Nacional de Águas e Saneamento Básico (Brasil). Conjuntura dos recursos hídricos no Brasil 2020: informe anual. Brasília: ANA, 2020.

ANGELAKIS, A. N.; ASANO, T.; BAHRI, A.; JIMENEZ, B. E.; TCHOBANOGLOUS G. Water Reuse: From Ancient to Modern Times and the Future. Frontiers Environmental Science, v. 6, n. 26, 2018.

ANJOS JR., A.H. Gestão estratégica do saneamento. 1 ed. Barueri: Manole. 2011.

ARAUJO, B. M.; SANTOS, A. S. P.; PAVAN, F. Comparativo econômico entre o custo estimado do reúso de efluente de ETE para fins industriais não potáveis em comparação ao valor da água potável para a região sudeste do Brasil. Exatas \& Engenharias, v. 7, n. 17, 2017.

BNDES. Banco Nacional do Desenvolvimento. BNDES Finem - Saneamento ambiental e recursos hídricos. Disponível em:

https://www.bndes.gov.br/wps/portal/site/home/financia mento/produto/bndes-finem-saneamento-ambientalrecursos-hidricos. Acesso em 27 jan. 2020.

BRASIL. Lei Federal n. 8.666 de 21 de junho de 1993. Institui normas para licitações e contratos da Administração Pública e dá outras providências. Diário da República, $1^{\text {a }}$ série - n $116,1993$.

BRASIL. Lei $\mathbf{n} \mathbf{0}$ 14.026. Atualiza o marco legal do saneamento básico e altera as Leis $n^{\circ}$ 9.984/2020, no 10.768/2003, no 11.107/2005, no 11.445/2007, no 12.305/2010, no 13.089/2015, no 13.5029/2017. Diário Oficial da União, Brasília, 15 de julho de 2020a.

BRASIL. Ministério do Desenvolvimento Regional. Secretaria Nacional de Saneamento - SNS. Sistema Nacional de Informações sobre Saneamento: 24ำ Diagnóstico dos Serviços de Água e Esgotos - 2019. Brasília: SNS/MDR, p. 183, 2020b.
CAIXA. Saneamento para todos. Saiba mais.

Disponível em: <

http://www1.caixa.gov.br/gov/gov_social/municipal/assi stencia_tecnica/produtos/financiamento/saneamento_p ara_todos/saiba_mais.asp>. Acesso em 27 jan. 2020a.

CAIXA. FINISA - Financiamento à Infraestrutura e ao Saneamento. Financiamento à infraestrutura e ao saneamento com processos de contratação e prestação de contas ágeis e simplificados. Disponível em: <https://www.caixa.gov.br/poder-

publico/modernizacao-

gestao/finisa/Paginas/default.aspx > . Acesso em 27 jan. 2020b.

ECHTERNACHT, T. H. de S.; QUANDT, C. O. A gestão do conhecimento como suporte ao processo estratégico na administração pública municipal: um estudo comparativo de casos no Brasil e em Portugal.

Perspectivas em Gestão \& Conhecimento, João Pessoa, v. 7, Número Especial, p. 35-49, mar. 2017.

EMBASA. Empresa Baiana de Águas e Saneamento. Solicitação de Propostas no 052-2019 (Licitação Internacional). Anexo I - Termo de Referência. Estudo de avaliação das potencialidades de reúso de efluente sanitário tratado no estado da Bahia. Disponível em: http://www.iica-

ecuador.org/ftp/tdrs_Brasil/EDITAL_SOLICITA\%C3\%8 7\%C3\%830\%20DE\%20PROPOSTAS\%20N\%C2\%BA \%20052-2019_PUBLICADO.pdf. Acesso em: 24 de fev. 2021.

FIELDING, K. S.; DOLNICAR, S.; SCHULTZ, T. Public acceptance of recycled water. International Journal of Water Resources Development, 1-36, 2018

FONSECA, A.; GABRIEL, C. F. Análise da influência da tarifação em seis indicadores operacionais e de qualidade dos serviços de abastecimento de água no Brasil. Eng. Sanit. Ambient., v. 20, n. 2, 2015.

FUNASA. Fundação Nacional de Saúde. Termo de referência para elaboração de plano municipal de saneamento básico. Instrumento de apoio da Cooperação técnica da Fundação Nacional de Saúde Funasa/MS 2018.

LEITE, L. de O.; REZENDE, D. A. Modelo de gestão municipal baseado na utilização estratégica de recursos da tecnologia da informação para a gestão governamental: formatação do modelo e avaliação em um município. Revista de Administração Pública, v. 44, n.2, p.459-493, mar/abr 2010.

MARIN, P.; TAL, S.; YERES, J.; RINGSKOG, K. Water Management in Israel: Key Innovations and Lessons Learned for Water Scarce Countries. World Bank, Washington, DC. 2017. 
MARTINS, E. G. P.; SOUZA NETO, J. Mensuração do Engajamento das Partes Interessadas em Projeto na Visão do Gerente de Projeto e das Próprias Partes Interessadas. Revista de Gestão e Projetos, [s. I.], v. 08, n. 01, p. 42-56, 2017.

MELO, M. C.; PEREIRA SANTOS, A. S.; PINHEIRO SANTOS, N. A.; MAGALHÃES DE ARAÚJO, B.; ROSA SILVA DE OLIVEIRA, J.; RIBEIRO CAMPOS, A. Evaluation of potential use of domestic treated effluents or irrigation in areas subject to conflicts over water use in Paracatu River Basin. Caminhos da Geografia (UFU. Online), v. 21, p. 52-63, 2020.

MORAES, D. L.; SANTOS, A. S. P.; BILA, D. M.; SILVA JÚNIOR, L. C. S.; ARAUJO, B. M. Análise comparativa de parâmetros hidráulicos para dimensionamento de tecnologias em Estações de Tratamento de Esgoto. Revista Internacional de Ciências, v. 10, p. 22-41, 2020.

MUKHERJEE, M.; JENSEN, O. A comparative analysis of the development of regulation and technology uptake in the US and Australia. Safety Science, v. 121, p. 5$14,2020$.

SANASA. Sociedade de Abastecimento de Água e Saneamento. Água de reúso. Disponível em: http://www.sanasa.com.br/servico/aguaReuso.aspx?f= A. Acesso em: 12 fev. 2021.

SANTOS, A. S. P.; VIEIRA, J. M. P. Reúso De Água Para O Desenvolvimento Sustentável: Aspectos de regulamentação no Brasil e em Portugal. Revista Eletrônica de Gestão e Tecnologias Ambientais, v. 8, p. 50-68, 2020.

SPEERS, A. Bonn Charter Principles Series n. 4 The Price of Water. p. 1-4, 2007.

UN. United Nations. Sustainable Development Goal 6 Synthesis Report 2018 on Water and Sanitation. New York. 2018. 